\title{
MULTI-YEAR SEA-ICE CONCENTRATION DERIVED FROM MODEL SIMULATIONS AND SATELLITE-MICROWAVE IMAGERY
}

\author{
(Abstract) \\ by \\ John E. Walsh \\ (Department of Oceanography, Naval Postgraduate School, Monterey, CA 93943, U.S.A.) \\ and \\ H.J. Zwally \\ (Laboratory for Oceans, NASA Goddard Space Flight Center, Greenbelt, MD 20771, U.S.A.)
}

\begin{abstract}
The Hibler ice model is formulated to include multi-year as well as first-year sea-ice concentrations. The multi-year ice coverage simulated by the model for the years $1978-85$ is compared with corresponding satellitederived coverage in the central Arctic and five subregions. The satellite data are obtained from the Nimbus-7 SMMR (Scanning Multifrequency Microwave Radiometer).

Changes of the regional multi-year coverage are compared on a monthly and seasonal basis for the non-summer seasons, and the model results are used to extend the microwave results to the melt season. The model-derived changes due to advection and convergence/
\end{abstract}

\begin{abstract}
divergence are distinguished from the melt-induced changes in order to assess the relative importance of model dynamics and thermodynamics to the normal seasonal cycle and the inter-annual variability of the simulated multi-year ice. Extreme deformation events that have produced long-lived signals in the microwave imagery are examined quantitatively by comparisons of model- and satellite-derived changes of multi-year coverage over synoptic time-scales. The model/satellite discrepancies on these shorter time-scales are diagnosed in terms of buoy measurements and the environmental parameters used to drive the model.
\end{abstract}

\section{DYNAMICS AND VARIABILITY OF PERENNIAL ARCTIC PACK ICE (Abstract)}

by

H. Jay Zwally

(Laboratory for Oceans, NASA Goddard Space Flight Center, Greenbelt, MD 20771, U.S.A.)

and

John E. Walsh

(Department of Atmospheric Sciences, University of Illinois, Urbana, IL 61801, U.S.A.)

\begin{abstract}
The mass balance and long-term variability of the perennial sea ice in the Arctic Ocean are of interest as indicators of the state of the Arctic sea-ice pack. The area of ice cover during summer has long been recognized to have a significant influence on the heat balance of the Arctic. In fact, various studies have focused on the possibility and consequences of decreases, or disappearance, of the summer ice pack. In contrast, in winter, the entire Arctic Ocean is covered with a compact ice cover and, therefore, variations in the maximum Northern Hemisphere sea-ice cover are determined primarily by conditions in the Bering, East Greenland, Barents, and other marginal seas. The primary factors determining the amount of multi-year
\end{abstract}

ice, which is ice that survives the summer melt season, are the growth in thickness during winter, summer ablation, and ice export mainly through Fram Strait. In this paper, the total area of multi-year ice in the Arctic Ocean from 1979 through 1986 is determined using passive microwave imagery from the Nimbus-7 satellite. The variations in the total multi-year ice area in several regions are described and compared with calculations of the divergence of the ice pack using the University of Washington Arctic Ocean Buoy data. From 1979 to 1981 , the total observed multi-year ice decreased about $15 \%$, remained low through 1982 and 1983, and recovered to previous values during 1984 and 1985. 